\title{
Current Status of Implementing Pension Insurance System for Urban and Rural Residents and Solutions
}

\author{
Shufeng $\mathrm{Ni}$ \\ Jilin Agricultural University \\ 512375850@qq.com
}

Keywords: Rural and urban residents; Pension insurance; Current status; Solutions

\begin{abstract}
In the past, there was rich labor market in China, so the product cost was relatively low with huge advantages in the international market, and China's economy developed rapidly. But in recent years, China's labor market is gradually narrowing, it boils down to is because of the severe aging in our country. The serious consequences of aging are the burden of young people, to reduce the burden on young people, it is important to improve the old-age insurance system for urban and rural residents. The emphasis of this paper is to study the pension insurance system for urban and rural residents of our country implementation present situation, summarize the implementation of the problems existing in the process, and according to the actual situation put forward reasonable countermeasures and expectations can effectively improve the old-age insurance system. The pension issues of China's urban and rural residents can be improved.

With the aging China's population and the implementation of family planning, young people have huge life pressure, especially in terms of the elderlies' pension. Thus, the Chinese government reforms the pension insurance system and introduces new pension insurance system for urban and rural residents. However, there are some problems in implementing this system, so only by solving these problems can be promote the smooth implementation of pension insurance system for rural and urban residents.
\end{abstract}

\section{Introduction to Pension Insurance System for Urban and Rural System}

Insurance Range. China's urban and rural residents in the current endowment insurance system clear the scope of the insured, including "reached the age of 16 years of age (excluding students), non-state organs and institutions of staff and does not belong to the basic pension insurance system covering urban and rural residents in the range can be in residence in the urban and rural residents' endowment insurance. Scope of insurance relative to prior to the implementation of urban and rural pension insurance system, more specifically, relates to urban and rural residents are more widely can be said that the realization of the ultimate goal of universal coverage of social security.

Payment Grade. Urban and rural residents pension insurance system provide a new premium grade, from 100 yuan to 2000 yuan a total of twelve grades. In addition to the provisions of the pay grade, giving Provincial People's governments of the right to freedom, can according to the local actual situation to increase the level of payment, of course, pay grade is the highest limited, in principle is not to be higher than the local flexible employment personnel to participate in the enterprise basic endowment insurance each year to pay the amount of the fee and the provincial government to increase their own pay grades also need to report to the relevant state departments for the record. The current implementation of the urban and rural residents of the insurance system, compared with the previous increase of 1500 yuan and 2000 yuan of these two grades, it can be said for the ability of urban and rural residents, can pay more for pension insurance.

Payment Incentive Mechanism. According to the introduction of China's urban and rural pension insurance system can be found, which clearly pointed out that the government needs in accordance with the insured to pay the cost of subsidies, that is individual pay cost more, more and more government subsidies, whereas the less. In addition, the collective should also be based on their own actual situation of the individual to give certain subsidies, but also to encourage those conditions are relatively good community to the community public welfare funds into the scope of 
the community. Encourage multi-channel access to pension funds, in addition to the government, the collective and individual, but also to encourage charitable organizations, other social and economic organizations also pay for the insured to raise the pension insurance.

Personal Account Interest-Calculating System. The current our country urban and rural pension insurance system in the provisions of the personal account interest standard, in accordance with provisions of China's interest as interest standard. Through this provision, to better manage personal accounts, but also to be more in line with the requirements of the real situation, to better safeguard the interests of the insured person.

Personal Account Balance Inheritance Policy. Insurance system for urban and rural residents for individual accounts of the balance of the inheritance policy to make adjustments, new rules said that if the death of the insured person, then the balance of its individual account above can be in accordance with the relevant provisions of the law of our country by the heir to the succession, including the amount of government subsidies.

\section{The Current Status of Implementing Pension Insurance System for Rural and Urban Residents}

Since the implementation of the pension insurance system for urban and rural residents in China, there have been two years, in the past two years, the urban and rural residents pension insurance system in the implementation of the national. Has obtained the certain achievement in the process of implementation of the old-age insurance system for urban and rural residents in China, but there is no denying the fact that there are some very obvious problems, these problems make the implementation of old-age insurance system for urban and rural residents cannot play the desired effect, also cannot be achieved at the target. Through the investigation and study, we found that the implementation of the old-age insurance system for urban and rural residents in China is mainly focused on the following aspects.

Rural and Urban Residents Lack the Insurance Awareness. Originally introduced old-age insurance system for urban and rural residents is the ability to live in urban and rural non employees to provide pension benefits for, this is a very conducive to the policy of urban and rural residents, but in the real implementation of the, urban and rural residents' awareness of participation is very weak. Urban and rural residents lack of insurance awareness, is caused by a variety of reasons: first of all, the publicity for the implementation of urban and rural pension insurance system in urban and rural government is too small, a lot of urban and rural residents no fully understand the real content of the old-age insurance system for urban and rural residents; secondly, in the minds of many urban and rural residents, pension rely on government and society is a very tricky thing, in their minds, more still rely on their sons and daughters that pay endowment insurance must wait until the specified age can enjoy pension benefits, is a waste of money. It is because a lot of urban and rural residents in this kind of psychological, it leads to the insurance awareness is very weak. In addition, in many places, urban and rural residents because of all the changes cannot continue to pay endowment insurance, thus leading to the interruption of the insured, some of which are eventually end up with nothing definite.

The Strength of Pension for Urban and Rural Residents Is Low. According to China's current old-age insurance system for urban and rural residents, the insured for urban and rural residents, want to enjoy the pension treatment, the first age has provisions must be at least 60 years of age can be. Urban and rural residents living standards are not high, very susceptible to major diseases, the average life expectancy is relatively low, at about 75 years of age, which makes the treatment of urban and rural residents to enjoy the benefits of a relatively short time. In addition, urban and rural residents pension treatment is very low, aged 60 years of urban and rural residents, the pension is only 75 yuan per month, simply cannot meet the needs of daily life. It can be said, whether it is from the age of the treatment of the old age or the level of respect, urban and rural residents pension security efforts are very weak. 
Lack Legal Environment. Although China Ayutthaya introduced a pension insurance system for urban and rural residents, but is not introduced to match the laws and regulations, which makes the endowment insurance fund cannot achieve the laws in the management, lacking certain norms, to some extent, the management of urban and rural pension is a risk. At this stage, in charge of urban and rural residents of pension, in general is to pay to the bank, but bank deposit interest rates gradually reduced, sometimes considering some regional price rose to the level, and even appeared negative interest rates, so the existence of the bank's endowment insurance gold but not be able to add value even devalued. And in some areas, because of the lack of legal regulation, pension insurance fund management personnel of any misappropriation of endowment insurance gold, reach old-age insurance payment time do not paid on time, causing discontent among the urban and rural residents.

Financing Channel Is Single. For urban and rural residents, the pension insurance funds from three parts, namely, the individual, the collective and the government. The existing financing channels are relatively simple, so the funds obtained is limited, and sometimes even cannot play its due role.

Coverage Range Is Limited. China's urban and rural residents' endowment insurance system in the beginning of the implementation, the choice in the pilot provinces and cities, but in 2014, began to implement in the country. However, in the process of implementation, the coverage is limited, in the developed area efforts to implement is relatively large, remote areas in the Midwest enforcement is relatively small, even some provinces and cities haven't full implementation of old-age insurance system for urban and rural residents.

Regional Difference Is Relatively Large. In terms of economy, China can be divided into three parts, namely, the eastern, central and western. China's eastern economic development is very fast, and the economic development of the western region is very slow, in the middle between the two. Inequality of economic development leads to the income of urban and rural residents. Even in the same area, there is a big difference in the income of urban residents and rural residents. But according to the introduction of China's urban and rural pension insurance system, the country is in accordance with the implementation of the same standard, so for people living in economically underdeveloped areas or township residents, on pensions, completely unable to meet the basic needs of life.

\section{Measures to Solve the Issue of Pension Insurance for Urban and Rural Residents}

Improve Rural and Urban Residents' Insurance Awareness. At this stage, China's urban and rural residents are very weak, this is an important factor in the implementation of urban and rural resident's endowment insurance cannot be implemented smoothly, and therefore should improve the awareness of the insured. Want to improve the awareness of urban and rural residents insured, we must increase the publicity efforts of urban and rural residents pension insurance system, so that can make the majority of residents living in urban and rural areas to fully understand the pension system. Publicity should be targeted, so we should choose the appropriate channels of publicity. With the development of the network, publicity channels become very wide, for the network to compare circulation, in addition to choose TV, newspaper as a propaganda channel, but also can choose the network. But in my local network is not in circulation, then you can choose TV, radio and so on as a propaganda channel. Again is the establishment of the advocacy group, in charge of propaganda work, according to the work make the rewards and punishment system, in accordance with the completion of the work to determine the is to take the reward or punishment. Only in this way can give full play to the enthusiasm of the advocacy group, actively participate in propaganda work.

Improve the Strength of Pension Insurance for Urban and Rural Residents. Endowment insurance of urban and rural residents is relatively poor, which is the reason why the implementation of urban and rural residents' endowment insurance is not smooth, and this should improve the security of urban and rural residents' endowment insurance. For people living with 
difficulties, especially people with disabilities, should improve the standard of subsidies, and then is based on the income level of urban and rural residents to improve the treatment of pension.

Improve the Legal Environment. Along with the implementation of the policy, the relevant laws and regulations should be issued, to create a good legal environment for the implementation of the policy. First of all, we should standardize the implementation of the old-age insurance system for urban and rural residents, so that in the implementation of the time can be carried out in accordance with certain standards. Secondly, it should strengthen the management of endowment insurance fund internal control and external supervision and inspection efforts, so that it is fair, just and open. Once found that endowment insurance fund had embezzled phenomenon, then for personnel had embezzled give serious capital punishment, serious person is given detention administrative punishment, so as to ensure that the endowment insurance fund can timely and successful distributed to the hands of the urban and rural residents.

Expand the Financing Channels. In the existing financing channels, we should broaden the financing channels, in addition to the government, the collective and individuals, but also can choose the bank such financial institutions as the source of urban and rural residents endowment insurance fund. Even the government should increase investment in urban and rural residents pension insurance, for individuals, should be based on the actual living standards of the local pension insurance to determine the proportion of pension.

Expand the Coverage Range. China should implement pension insurance system for rural and urban residents nationwide, and strengthen the supervision and management at those remote regions to make sure that the pension insurance system for urban and rural residents can be implemented according to policies formulated by the central government. For those regions that do not implement the pension insurance system for rural and urban residents according to the regulations, penalty should be given to relevant personnel.

Differentiate Treatment of Regional Differences. Because China's economic level differences between the various regions are relatively large, which led to the implementation of the same old age insurance system is not able to ensure that all urban and rural residents can meet the needs of daily life. In China's economically developed areas, should improve the personal pension insurance to pay the cost, so as to improve their retirement to enjoy the treatment of the elderly. For living in economically underdeveloped areas of urban and rural residents, in addition to the individual to pay pension costs, the government should increase subsidies. For people living in an area of urban and rural residents, should also according to the specific circumstances of the cities and towns to determine how should be implemented, so as to ensure each region can enjoy in accordance with local economic development level of pension benefits.

Endowment insurance is always the most important people's livelihood problem in our country, for urban and rural residents without work, endowment is a big problem, and many residents have no income after working age to guarantee the basic life. Therefore, our country has introduced urban and rural residents to keep the old insurance system. The system is first implemented in some provinces and cities as a pilot, and then extended to the whole country. In this process, the implementation of old-age insurance system for urban and rural residents despite certain achievements, but also exposed the problems existing in the process of implementation. Therefore, it is necessary to solve these problems, the endowment insurance system for urban and rural residents can really bring the gospel for urban and rural residents endowment.

\section{References}

[1] Hao Xiaoyan. Current Status of Implementing Pension Insurance System for Urban and Rural Residents and Solutions [J]. Human Resource Management, 2016, 06:226.

[2] Wang Weijun. Problems in Implementing Pension Insurance System for Urban and Rural System and Solutions -Take the Example of Anhua County [J]. Journal of Hunan Administration Institute, 2015, 02:16-19.

[3] Wang Yin, Xu Xiaoting, Chu Xue. Review of Research into Social Pension Insurance for Urban 
and Rural Residents [J]. Labor Guarantee World, 2015, S2:117-119.

[4] Deng Sasong, Xian Mihua. Problems in Implementing New Basic Pension Insurance System for Urban and Rural Residents and Countermeasures [J]. Economy Review, 2015, 09:8-12.

[5] Yang Jinqiu, Ma Xiaoli, Yue Ling. Research into China's Pension Insurance System for Urban and Rural Residents [J]. Cooperative Economy and Science and Technology, 2015, 24:182-184.

[6] Liu Ting. Current Situation and Problems of China's Pension Insurance System for Urban and Rural Residents and Solutions [J]. Scientific and Technological Entrepreneurship Monthly, 2007, 11:164-165.

[7] Yan Lingshuai, Wu Zhong, Xiang Tian, Zhi Yunqiu. Labor Guarantee World (Theory Edition), 2012, 11:49-52.

[8] Zhao Qian. Practice and Feedback: Analysis of the Adaptability of Social Pension System in Rural Areas [J]. Journal of Yunan Minzu University (philosophy and social science edition), 2016, 01:106-123.

[9] Chen Chen, Fang Jin. Research into the Implementation of Pension Insurance Policies for Rural and Urban Residents -Take the example of Ningyang County [J]. Journal of Shanxi Agricultural University (social science edition), 2016, 02:95-99.

[10]Huang Xingliang, Zhan Yufeng, Kong Hao, Bai Jingkun, Deng Jinshu. Research into Problems of Implementing Social Pension Insurance for Rural and Urban Residents - Take the example of Zhouzhou, Hebei Province [J]. Labor Guarantee World, 2015, 27:4-5+11. 